\title{
Memorias del Habitar: Las Condiciones de Vida en el Trabajo en Fábricas Textiles en San Agustín Etla Oaxaca
}

\author{
Memories of Inhabiting: Living Conditions at Work in Textile Factories in San \\ Agustín Etla Oaxaca \\ Memórias de Habitar: As Condições de Vida no Trabalho nas fábricas \\ têxteis de San Agustín Etla Oaxaca
}

Rosa María López Oliver Farías

Arquitecta, M.Sc. Arquitectura, Ph.D en Arquitectura

en el Área de Restauración de Sitios y Monumentos.

Universidad Anáhuac de Oaxaca, México

rosa.lopezo@anahuac.mx

(iD) https://orcid.org/0000-0002-6155-2808

\section{RESUMEN}

El objetivo de esta investigación fue rescatar y analizar las memorias del habitar. Se realizó una búsqueda histórica sobre el sentimiento de pertenencia de los obreros en el ramo fabril, partiendo desde su pasado. Para esto, se llevaron a cabo entrevistas en profundidad bajo un esquema deductivo de aquellas personas que vivieron y participaron como trabajadores de las fábricas de textil de hilados y tejidos de San José y Soledad Vista Hermosa. Esta investigación fue efectuada del 2018 al 2019, en la comunidad de San Agustín, localizada en la parte central del Estado de Oaxaca, en la Región de los Valles Centrales, perteneciente al Distrito de Etla.

Palabras clave: Memorias; habitar; pertenencia; fábrica textil.

\section{ABSTRACT}

The objective of this research was to rescue and analyze the memories of inhabiting. A historical search was carried out on the feeling of belonging of the workers in the manufacturing sector, starting from their past. For this, in-depth interviews were carried out under a deductive scheme of those people who lived and participated as workers in the textile yarn and fabric factories of San José and Soledad Vista Hermosa. This research was carried out from 2018 to 2019, in the community of San Agustín, located in the central part of the State of Oaxaca, in the Central Valley Region, belonging to the Etla District.

Keywords: Memories; living; belonging; textile factory. 


\section{RESUMO}

O objetivo desta pesquisa foi resgatar e analisar as memórias de habitar. Realizou-se uma pesquisa histórica sobre o sentimento de pertencimento dos trabalhadores do setor manufatureiro, a partir de seu passado. Para isso, foram realizadas entrevistas em profundidade sob um esquema dedutivo com as pessoas que viviam e participavam como trabalhadores nas fábricas de fios e tecidos de San José e Soledad Vista Hermosa. Esta pesquisa foi realizada no período de 2018 a 2019, na comunidade de San Agustín, localizada na região central do Estado de Oaxaca, na Região do Vale Central, pertencente ao Distrito de Etla.

Palavras-chave: Memórias; vivência; pertencimento; fábrica têxtil.

\section{INTRODUCCIÓN}

La tradición textil en la Nueva España se remota desde la Época Prehispánica hasta nuestros días, a partir de la Evolución Industrial en Europa que comienza en la segunda mitad del siglo $\mathrm{XVIII}$, se convierte en un factor que alcanzó su máximo desarrollo en el sector manufacturero, sustituyendo la mano artesanal por tecnologías más productivas, utilizando energía hidráulica y de vapor. Manuel Miño (1983) nos comenta, al respecto, que es de reconocer que México tenía la industria más grande y moderna de Latinoamérica, llegando a compararse con algunas fábricas europeas. Puntualiza que el obraje fue una de las instituciones económicas de mayor relevancia en la Nueva España, ya que representó la unidad de producción de tejido de lana más importante en la colonización, por lo menos en los dos primeros siglos después del poblamiento español.

El fundamento más significativo del proceso de génesis del capitalismo puede ser observado en el desarrollo de la industria textil, debido a que fue una de las primeras actividades económicas que se desarrollaron, propiciando así los primeros indicios de acumulación capitalista que marcaron el despegue de la industria en México (Arroyo \& Cárcamo 2010, p.52).

Al mediar el siglo XIX, se establecieron las primeras fábricas que definieron el despegue de la industria, aunque con una marcada estructura artesanal. Esto conllevó a que la industria textil tuvo un papel de suma importancia en la Revolución Industrial; fue una de las actividades industriales que representaron un eslabón en el segmento económico, principalmente en los países de desarrollo.
El desarrollo industrial en México comienza a partir de 1830. Para 1837, se crearon cuatro fábricas modernas de hilados en Puebla, con 8.000 husos, y para 1844 existían ya 47 fábricas en todo el país, con 113. 813 husos. Durante mucho tiempo, se tejía mediante prácticas antiguas artesanales (Arroyo \& Cárcamo 2010). La mayoría de la maquinaria textil era importada de los Estados Unidos, Inglaterra y Francia, y eran movidos en principio por medio de energía hidráulica, por lo que estos complejos industriales se ubicaban en las márgenes de ríos que fueran caudalosos. Una de las crisis del siglo $X X$, que dejaron una huella imborrable en el sector económico, fue la de 1907 en Estados Unidos y en varios países, entre ellos México, en donde el pánico bancario y bursátil disminuyó las operaciones financieras, provocando una reducción en las inversiones estadounidenses en el país (Anaya, 2002 citado en Tello, 2009), afectando a los sectores económicos mexicanos, relacionados con el sector de exportación, la industria de la transformación y los servicios, entre ellos el bancario, en donde algunos de ellos se vieron obligados a cerrar sus operaciones.

Cabe destacar que esta crisis, correspondiente a 1907, perturbó severamente la sociedad industrial mexicana, debido principalmente a los sueldos bajos que percibían los obreros, reducción de horas de trabajo, despidos de laborantes, la exigencia al buen trato en la fábrica y los cambios tecnológicos introducidos por la industria afectaban la relación del artesano con la producción, originando nuevas formas de organización obrera. La incertidumbre laboral de la crisis y el debilitamiento de las estructuras de poder gubernamental prepararon el escenario para una efervescencia organizativa (Camarena, 2001). 
Oaxaca no fue la excepción. A pesar de sus circunstancias históricas a lo largo del siglo XIX, tuvo la capacidad de transformarse como sociedad y proyectar estos cambios en todos sus ámbitos, tanto en la ciudad rural como en los centros urbanos de la ciudad. Neri (2004) nos indica que la economía en el estado de Oaxaca estuvo en esa época muy ligada a la economía global, debido principalmente al gran número de empresarios extranjeros que invirtieron en nuestro país en la última década del porfiriato. Esto dio origen al establecimiento de varias familias de españoles, primero, y posteriormente franceses e ingleses que se asentaron en este valle para explotar su riqueza. Víctor Martínez (1985) menciona que la opulencia y prosperidad en el lugar no tardó en quebrantarse. Entre la primera y segunda década del siglo XX, existían tres industrias textiles: la de San José, propiedad de los Trápaga; la de Vista Hermosa perteneciente a José Zorrilla; y la factoría de Xía, localizada en Ixtlán, propiedad de Mowatt y Grandison. Remarcando nuestro tema de estudio en las dos primeras fábricas textiles ubicadas en la misma localidad.

Es importante resaltar que esta comunidad de San Agustín (Figura 1), después de haber sido un pueblo agrícola pasó a ser agrícola industrial y que a partir de este nuevo giro se dio un cambio en la estructura del pueblo, convirtiéndolo en uno de los pueblos más prósperos del Valle de Etla, en donde tuvieron que aprender a convivir con otras personas que venían de otras partes del mundo.

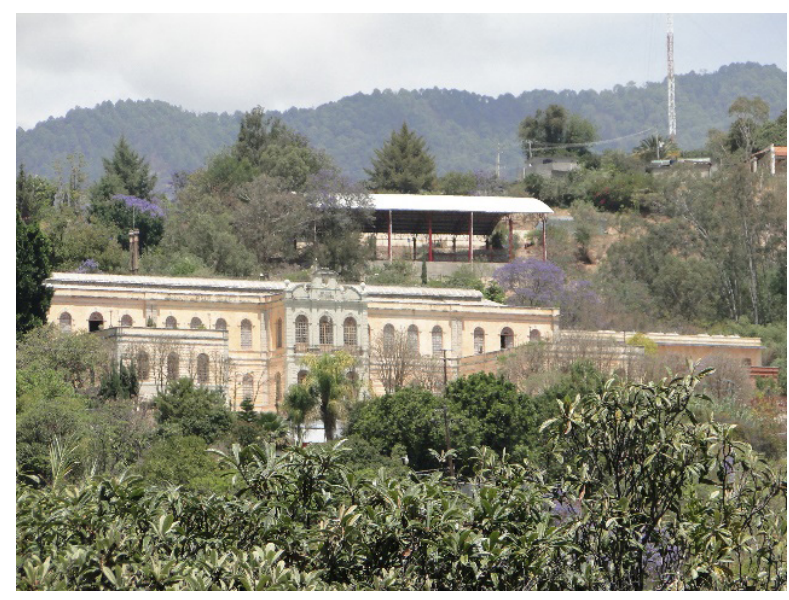

Figura 1. Ex Fábrica de Hilados y Tejidos Soledad Etla hoy Centro de las Artes San Agustín Etla Oaxaca. Fuente: Archivo fotográfico propiedad de la autora 2019.
José Zorrilla Sáenz Trápaga fundó en 1873, junto con sus primos Juan Sáenz y los Cajiga, la fábrica de Hilados y Tejidos "San José"; diez años después, en 1883, fundaría la fábrica de hilados y tejidos "Soledad Vista Hermosa", adjunta a la fábrica San José, así como la hidroeléctrica del mismo nombre (Velasco 2011). Estas nuevas fábricas se ubicaron cerca de corrientes acuíferos emplazadas en las faldas de la Sierra de San Felipe, en la cañada que conduce al río San Agustín, llamado anteriormente Río Grande.

La reconstrucción de los hechos históricos de ambas fábricas de hilados y tejidos de "San José" (Figura 2) y de "Soledad Vista Hermosa", fueron apoyados a partir de los artículos publicados en los diarios locales en Oaxaca, permitiendo tejer la historia laboral, social y económica que experimentaron estos centros fabriles. Los datos recuperados corresponden a los periódicos El Oaxaqueño, Oaxaca Gráfico, El Chapulín y el Imparcial. $Y$ es de precisar que corresponden a los años de 1936 a 1960, debido a que los rotativos anteriores a esa fecha no se localizaron en la hemeroteca del Estado, y los años posteriores dejaron de interesarse en la situación fabril. A principios de siglo $\mathrm{XX}$, y de acuerdo con la revista local "Oaxaca y Puebla llustrada", la fábrica de Vista Hermosa era propiedad de José Zorrilla y su bonanza era extraordinaria, a tal punto que se había cubierto la necesidad de crear el turno nocturno. Contaba con 200 telares y 6000 husos, dando trabajo a más de 400 obreros. La calidad de sus productos en hilados blancos y de color, tanto de las mantas, driles, orgacines y telas reconocidas como Vichy, fueron garantes para el premio que se otorgaría en la Exposición Universal de 1900 a la empresa textil (Southworth, 1901).

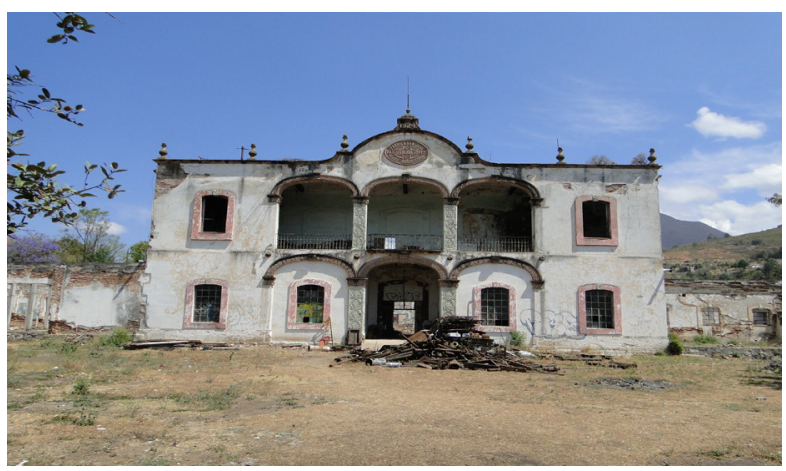

Figura 2. Ex Fábrica de Hilados y Tejidos San José. Fuente: Archivo fotográfico propiedad de la autora 2019. 
Los hechos de la tercera década manifiestan acontecimientos que implican el necesario cambio del sistema patronal. La formulación de sociedades colectivas fue un requerimiento unísono de las industrias que existían en ese momento. El Lic. Don Rafael Márquez Toro, representante del foro oaxaqueño, dictaminó en un estudio la necesidad de implementar el reglamento del Párrafo III del Artículo 27 constitucional, en beneficio de los trabajadores, para que estos pudiesen explotar la producción de las fábricas, a través de la formación de sociedades cooperativas (Diario "El Oaxaqueño"1936). Ese mismo artículo del diario local, especifica la necesaria reapertura de labores, puesto que por más de una década ha permanecido en cese: "... La citada fábrica está parada y suspendió su actividad el $1^{\circ}$ de enero de 1923, lo cual puede comprobarse por la manifestación de clausura presentada, para efectos fiscales ante la recaudación de rentas de Etla...la Fábrica aludida es de los señores Zorrilla Sucesores, S. en C. actualmente en liquidación..." (Diario "El Oaxaqueño", 1936).

Por lo anterior, puede interpretarse que, para la segunda mitad de la tercera década de 1900, la factoría no solo no producía los 600 kilogramos de mantas del número 50 y 80 ; sino que la situación era incosteable gracias a la deuda que el propietario tenía con el departamento de recaudación de rentas del distrito de Etla. Al cerrar las puertas en esta fábrica, la mayoría de los artesanos se ubican a trabajar en la Fábrica de San José, en la misma localidad.

\section{MÉTODO}

Desde una metodología cualitativa, esta investigación tiene un acercamiento a los testimonios de padres e hijos que trabajaron como obreros en los últimos años en las fábricas antes que se declaran en quiebra, en donde dichas entrevistas son fundamentales para analizar la problemática planteada como aquel sujeto que habita y se desarrolla en un espacio fabril, revisando sus condiciones laborales, familiares y humanas. En este sentido, Izcara (2014, p.35), menciona que el proceso de acopio de datos cualitativos, denominado "trabajo de campo", implica que el investigador deba pasar largos períodos en una comunidad, organización, u otro entorno social, donde se observen conductas, interacciones, conversaciones y entrevistas a los actores sociales y recopilación de documentos de interés, partiendo de fuentes primarias.

Lugar de Estudio. "Fábrica de Hilados y Tejidos en San José" y "Soledad Vista Hermosa" ubicadas en San Agustín Etla, Oaxaca.

Sujetos de Estudio y la Ética. El Universo consistió de 55 personas que actualmente se encuentran vivas, pero lamentablemente no todas gozando de buena salud; se seleccionaron a siete personas ricas en información que mostraron una gran disposición a participar en el estudio, en donde se les explicó los motivos del trabajo de investigación obteniendo su consentimiento (Hogg \& Vaughan, 2010), únicamente personal de sexo masculino, entre las edades de 75 a 90 años de edad, que trabajaron en ambas fábricas, oriundos de la propia comunidad de San Agustín Etla, que vivieron de cerca el ámbito laboral y estuvieron presentes en la decadencia de las factorías. Se explicó a dichos participantes el propósito de la investigación, exclusivamente académico, así como también el guardar confidencialidad en su participación.

La Técnica. En esta investigación se realizaron "entrevistas en profundidad" cuyo objetivo fue lograr adentrase en la vida del otro, penetrar y detallar en lo trascendente, descifrar y comprender los gustos, los miedos, las satisfacciones, las angustias, zozobras y alegrías, significativas y relevantes del entrevistado; en el que consiste en construir paso a paso y minuciosamente la experiencia del otro. Este tipo de entrevista sigue el modelo de plática entre iguales, "encuentros reiterados cara a cara entre el investigador y los informantes" (Taylor y Bogdan, 1990 p. 101), en donde nuestros participantes expresarán al respecto de sus vidas, experiencias o situaciones, tal como las enunciaron con sus propias palabras.

\section{RESULTADOS}

Una historia se construye de momentos, y cada uno de ellos van siendo eslabones importantes que marcan las vidas de quienes se encuentran en una época específica, junto con sus familias e historias personales, dentro de un ambiente propio, su cultura, formas de vestir, de comer, convivir, sus valores e historias, tal como nos lo citan Hogg M. \& Vaughan G. (2010) cuando nos hablan sobre como lo que pensamos, en cómo nos sentimos, cómo nos vestimos, qué y cómo comemos, que 
valores y principios morales sostenemos, cómo interactuamos entre nosotros, como interactuamos entre nosotros y como comprendemos el mundo que nos rodea, la cultura invade casi todos los aspectos de nuestra existencia, Tal vez por eso la cultura es el trasfondo aceptado de antemano de nuestra vida cotidiana (p.101).

Si logramos entrar al diálogo anterior nos daremos cuenta de la realización de trabajo y la certeza de las palabras de Clay \& Wakeley (1988), al citar que el trabajador es parte de un sistema hombre-máquina y también de un sistema hombre-hombre. Es la máxima responsabilidad del ejecutivo organizar a la gente de su encuadre social en la forma en que sea más efectiva. Si lo hacen sin efectividad, él y los suyos irán al fracaso, si lo hace con certeza, irán al éxito. Lo cierto es que nadie puede saber qué es una buena organización humana, ni cómo se crea. De aquí, la importancia de mencionar que las investigaciones de los científicos sociales están dando algunas guías para hallar las respuestas. Sería importante preguntarnos en qué momento se instalan los valores en medio de los líderes y trabajadores en donde éstos últimos expresarán, desde su modo de vivir y habitar, el trabajo que desempeñaban, sus experiencias de vida; desde el aprendizaje, sus necesidades, las ganas de superarse, el lugar, la convivencia en sus espacios, las máquinas y sus usos, hasta la sensación de pertenencia, la hermandad como el caso de Rufino.

\section{Agradecimiento y memorias de habitar, dos emociones en el juego de la vida y el trabajo}

Yo entré a trabajar a la edad de 15 años en 1955, ahí trabajé 34 años; en el 89 paró la fábrica, inicié como aprendiz, había un patrón y a los que trabajaban les pagaban un sueldito, yo estaba dentro de los que entraron en ese año, chamaco, casi se acabó parte de mi vida hasta los 44, pero, gracias a ese trabajo a esa fabriquita, fueron creciendo mis hijos, estudiaron un poquito y salí un poquito adelante y yo todavía estoy todavía gracias a Dios. De la edad que tenía yo para atrás había personas mayores, yo era tejedor, hacíamos manta cruda, la empacábamos y la mandábamos a México para estamparla, porque ese patrón tenía mucho dinero, distribuía mucho en México y la exportaba.

La juventud en el tiempo de producción, la capacidad de demostrarse que se puede aún en la adversidad, el valor de la paciencia y el ser parte del trabajo de la fábrica, que era lo más grande que existía en aquel tiempo y en aquella tierra, donde la abundancia del agua permitía expresarse en el trabajo constante, sin parar, con diferentes pensamientos, aportaciones, experiencias, ganas de salir aprender, y la paciencia, los pocos conocimientos que frente a las máquinas doblegaban cualquier voluntad para sumar, esfuerzos colectivos y exportar la manta.

Tenía el seguro social, entrabamos a las 6 de la mañana a iniciar labores, salíamos a las 9 a almorzar, comenzábamos a las 10 y salíamos a las 3 y media del primer turno, y entraba otro y salía 10 y media y salían 5 y media, no paraba para nada ¿eh?, había una turbina de 4 motores, y cada motor tenía su departamento que movía. Y el agua se va para Oaxaca. Esa turbina producía el movimiento, el tejido tenía la tela, y ya en preparación estaba otro motor a donde comenzaban a preparar el algodón, traía el patrón quien sabe de por dónde pero cada ocho días se llevaba la paca y así iba, y hasta allá en el fondo había un trabajador especial que estaba triturando el algodón porque venía por pacas, ya el batiente se encargaba de triturarlo mucho más, pasaba un rodillo que iban pasando con otra maquinaria y ya salían las pacas, caía a unos botes un material comprimido, y ya pasaba a las cargas, y ya salía un chorro de algodón, de ese bote pasaba al intermedio, y ahí pasaba a otra máquina, sacaba otro más delgado, de ahí entraba a los trociles, y salía el hilo, era muy bonito. Cuarenta y un pesos me daban por un turno. Fui oficial de 4 máquinas, el que estaba más anciano ya pasaba a 3 , y el joven lo iban ascendiendo, pues de 3 pasaba a 4, y si era competente de veras ya manejaba 6 , ya para manejar 6 tenía que ser uno muy ágil porque los telares estaban así, había que pararlo meter el hilo seguir trabajando, y no despegarse de las máquinas.

Si observamos su posibilidad para salir adelante, aportando en el individuo virtudes que lo enaltecen muy a pesar de las condiciones de pobreza en las que se encuentre trabajando, arduas horas para salir de su limitada condición, resulta hoy por hoy necesario observar las condiciones de vida para lograr ese pequeño cambio económico sostenido en base a grandes esfuerzos personales, muy significativo para él y su familia, para el mismo, la gratitud, la solidaridad, generando una forma de ir cubriendo la brecha entre la pobreza y la riqueza, tal como lo dice Jesús Olmedo Rivero, en su libro 
citando "en el informe Programa de las Naciones Unidas para el Desarrollo (PNUD-96) se nos plantea la urgente necesidad de erradicar la pobreza en el mundo, es un imperativo moral" (p.165).

Había tejedoras, unas dos mujeres, tenían dos mujeres, no había niños, solo de 15 años para arriba. El patrón quería un 10 por ciento para modernizar la fábrica, les pidió a los trabajadores, y algunos señores no quisieron, y ese señor tenía buenas intenciones, Manuel Gómez Portilla, era el dueño, y el administrador se llamaba Bernardo Pineda, y el Ing. Palacios Mateo Solana creo que fue el fundador, y ese señor le vendió a Don Manuel, y ese le vendió a otro y ese no era industrial y ellos no le entendían el teje y maneje de lo que era una industria, hasta que hubo uno que nos quedó a deber mucho dinero, y ahí nos dejó el inmueble con lo que le correspondía, nos lo dejaron. Un auge muy bonito, y ahí está el lugarcito. (Entrevista al Sr. Rufino febrero 2019).

Motivados por las emociones, y para entenderlo en el siglo XXI, resulta importante la "revolución afectiva" (Forgas \& Smith, 2003 y Haddock \& Zanna, 1999). La investigación se ha orientado de cómo los sentimientos (afecto, emoción, estado de ánimo) influyen en la cognición social y son influenciados por esta. $Y$ es ahí donde vemos ante mismos incidentes diferentes respuestas emocionales, incluso disparadas de un punto a otro, influyendo en aspectos de la persona, tales como el trabajo. La capacidad del trabajo, demostrada a través de sus actos, y sus alcances, una vez que el ser humano siente la fortaleza de encontrar la estabilidad en las necesidades básicas, trata de impulsarse y escalar hacia la escalera de la realización a través de su ejercicio de avanzar muy a pesar de los reveses. Ocasionando el diario perfeccionamiento en su quehacer, aumentando sus niveles de frustración en el alcance de sus sueños.

Otra experiencia desde la mirada de una generación más joven que aún trabajó en 1980.

Es una situación de frustración porque los señores fueron despojados de sus terrenos, engañados por la situación de la fábrica, por un lado, la vejez les ha hecho irse marchando anticipadamente, pero la lucha no la hemos terminado, la frustración surge cuando los nietos y los hijos los condenan e insultan, hay un choque de educación, de cultura y les afecta, independientemente estamos tratando de que se haga justicia. Porque se lo ganaron sus padres, hasta entonces se acaba todo. Pocas veces en el recorrido que he tenido pro algunas comunidades, he tenido la oportunidad de ver que los jóvenes respetan a los abuelos, a los padres, que curiosamente donde tantas vidas dieron estos viejitos, los tildan, los tachan, los humillan, y los ningunean. Ese esfuerzo no se paga. (Entrevista al Sr. Dokis febrero 2019). (Figuras 3 y 4).

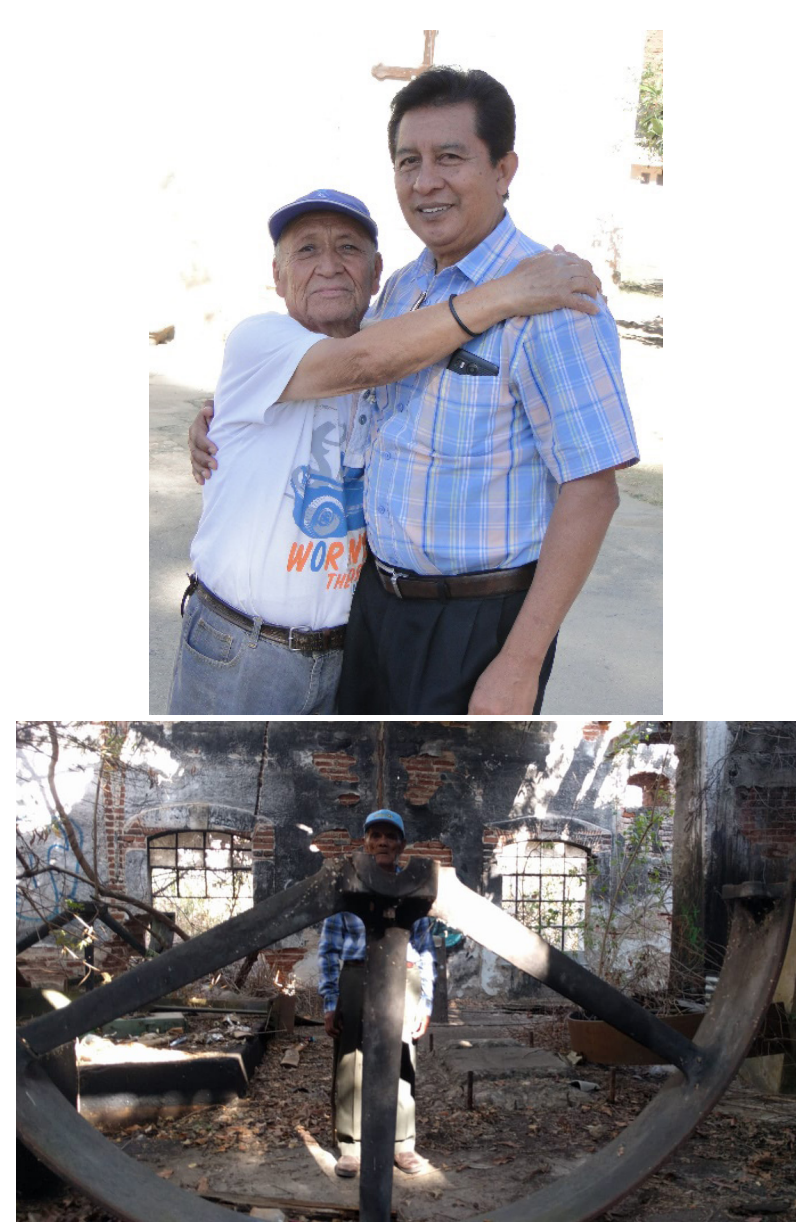

Figuras 3 y 4. Ex Fábrica Textil San José, generaciones vivas de obreros.

Fuente: Archivo Fotográfico propiedad de la autora 2019.

Hijos de operarios que trabajaron en la Fábrica en 1970.

Recordar hace que volvamos a vivir, aquí crecimos como niños, aquí crecí yo con mi padre, mi padre era electricista, en ese momento me fui enterando de las cosas que se manejaban política y socialmente, aquí 
hacer una fiesta de fin de año, era un derroche de dinero, tremendo, una fiesta, había mucha abundancia en ese entonces yo tenía 9 años, acompañaba a mi padre a efectuar los trabajos que tenía pendientes, los domingos, días festivos se cambiaban luminarias. No todos los niños tenían esa fortuna, esa oportunidad, yo por las características del trabajo de mi papá venía, lo acompañaba.

En el periodo del Sr. Solana era una festividad que la ponía el patrón, el pagaba la fiesta, como patrón, después los empleados les descontaban todo el año para la fiesta y tenían que cooperar con la fiesta patronal y el mismo proceso se hacía con la fiesta de San José, ahora es a través de cooperaciones, nos descontaban 25 pesos, y la gente estaba de acuerdo y aunque no estuviera de acuerdo tenían que cooperar. (Entrevista al Sr. Víctor, febrero 2019).

Muy a pesar de no cumplir todas las necesidades humanas, en aquella época de la pujanza de los textiles, la necesidad de superación alcanza diferentes poblaciones, trayendo entre los pueblos de la ciudad de Oaxaca, muchos hombres, algunos movidos por los afectos, tal cual lo cita Blascovhich y Méndez, "como la respuesta afectiva (emoción) es fundamentalmente una disposición para una forma de acción vinculada con apreciaciones de daño y beneficio, el proceso de apreciación es continuo y en gran medida automático" (Hogg- Vaughan 2010, p.72). Era muy importante la convivencia familiar y laboral al aire libre creando vínculos afectivos que dejaron huella en sus memorias.

\section{Pujanza económica y mercantil como realización hacia el bien común. Otro testimonio, desde la experiencia de vida de 1957, Maximiliano, fue de vivir en la fábrica desde muy niño.}

Nosotros conocimos a Don Baltazar Cruz, que era el dueño de la fábrica, él era dueño de la finca "Alemania", era como un hacendado de aquella época y en esa época tenía varias casitas que les daba a los trabajadores, nos fuimos para Vista hermosa en 1957, era un niño, mi papá era multi-oficios, era panadero, hortelano, zapatero, tenía muchísimas facultades, era más bien hortelano y flores lo que sembraba mi padre y de eso nos mantenía a todos. Nosotros fuimos 8 hermanos, yo fui el cuarto. Yo tenía 5 años, misteriosamente yo me acuerdo mucho de las fincas, y de todo eso, y tengo muy pegado lo de la fábrica.

Considerar el ambiente para trabajar y rendir con valores de lealtad, de forma óptima tiene que ser indispensables, para crear un ambiente lleno de respeto, admiración, trabajo constante, y responsabilidad, pero también, al mismo tiempo, la necesidad de los trabajadores comienza a satisfacerse lenta y progresivamente, guiados con un liderazgo que deja ver otras formas mejores de vida.

Se pusieron a huelga, no había el dinero suficiente y ahí empezó la huelga, 1960 se vino para abajo. Cerraron la fábrica, ocho meses sin trabajar, tuvieron que pagar sueldos caídos, el patrón ya no pudo pagar, los empleados se quedaron con la fábrica para explotarla, y para recuperar el dinero de los sueldos caídos. Ni siquiera había gente en vista hermosa, llegaron gentes de otros puntos, la trinidad, de Teococuilco, del punto, de la Sierra Juárez, alrededor de la fábrica, hay terrenos, hay unas casas que ya están derruidas, eran parte de la misma fábrica, a la gente que venía de fuera les daba cobijas sabanas, barro, lo que podía porque llegaban con las manos vacías, era un sistema como de hacienda, entre esa protección nos tocó a nosotros.

El esfuerzo de mantener una industria de tal dimensión requería la inversión como primer punto esencial, así también la calidad de los productos que efectúan, pero no solo eso, sino la calidad del trato que brindaba el dueño a sus empleados, para ser tomados en cuenta. La capacidad humana para acercarse a la gente, proveer hasta donde era posible, ver por las condiciones de salud, hasta donde el contexto histórico correspondía.

El pueblo merecía mejor destino, esa fábrica en vez de volverse chatarra se hubiera convertido en una empresa de punta. A veces no sabemos apreciar lo que tenemos hasta cuando lo tenemos perdido. El recuerdo que me deja es el florecimiento, la abundancia, el conocimiento de otros seres humanos que no son de un solo pueblo, porque el conocimiento de otros pueblos e individuos, son lecciones para nosotros como seres humanos, de diferentes pensares, estamos constituidos de la misma carne y la misma sangre. (Entrevista al Sr. Maximiliano marzo 2019). 
La abundancia que se vivía en aquel tiempo gracias al trabajo obrero era mucha y al parecer los tiempos marcan que el simple criticar y disputar no unen (Höffner J. 1990). La trascendencia de sus actos en las formas presentes. Como dice Ovejero Bernal (2015) somos un ser relacional. Y más que racionales, somos seres emocionales pasionales (Torregrosa 2010). Pensamos muchas veces que somos nosotros quienes en nuestro pensar individual decidimos nuestros actos más concretos, pero por ello es importante ver el entorno.

\section{Cultura, orgullo y pertenencia como sinónimos de seguridad y hermandad el cuidado por el otro}

Resulta muy importante entender que para que se desarrolle una cultura de cooperación e identidad, influye el colectivismo, que se define como la estructura de la sociedad y visión del mundo en la que la gente da prioridad a la lealtad, el compromiso y la conformidad con el grupo, y a pertenecer y adaptarse a grupos, respecto de sobresalir como un individuo aislado. Así también podemos observar que, en la siguiente experiencia, la fuerza de la identidad genera una forma de vida, propia de los elementos presentes en el ambiente, tales como las condiciones de vida, la organización de las familias en la comunidad, el sistema de red social, político que existía, así mismo citando nuevamente a HoggVaughan (2010), que para que una cultura entera florezca, necesitará una red de sistemas de apoyo, legal, político y económico (Cohen 2001).

Félix (ahora Esteban, figura 5).

Mi trabajo fue tejedor, 1940, nací en la sierra, Teococuilco de Marcos Pérez. Los patrones eran buenos muy a pesar de que nosotros teníamos nuestro sindicato, el primer patrón se llamó Mateo Solano, la fábrica tiene una placa, fue el dueño por segunda vez, porque estaba todo abandonado, trajo las máquinas y el segundo patrón terminó de reparar en 1924. Luego empezó a trabajar porque ya estaban las maquinas, lo que hizo el segundo patrón es que empeño a limpiar las máquinas y él puso techo las paredes ya estaban, lo que se callo fue los techos. El nuevo techo. Doy razón nomas del segundo, Casi casi si trate con el segundo patrón, trabajaron 3 turnos, primer turno, segundo turno y tercer turno, yo estaba en el $2^{\circ}$. Turno, eran como 350 obreros.

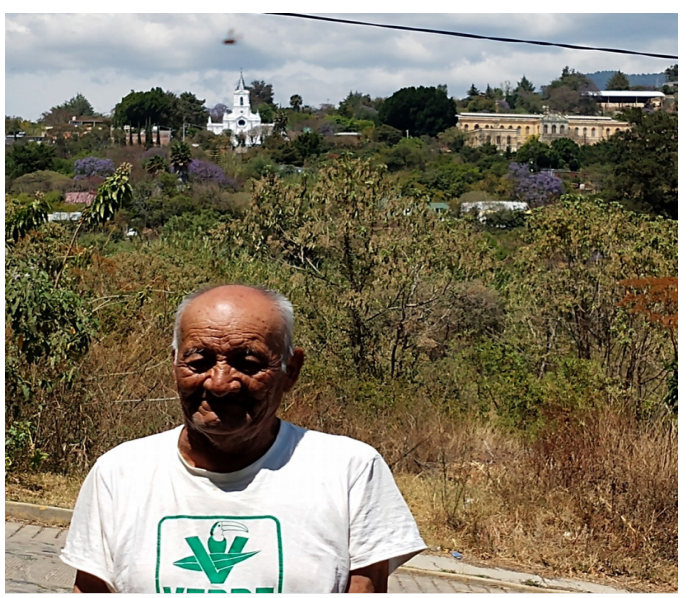

Figura 5. Vista al fondo de la Ex Fábrica Soledad de Vista Hermosa y su iglesia, San Agustín Etla, junto con Don Félix. Fuente: Archivo fotográfico propiedad de la autora 2019.

La fábrica de San José era de adobe, pero ya el techo se fue para abajo. Existieron dos plantas eléctricas una acá, y otra en el río acá hay mucha agua, por eso este pueblo es orgulloso porque tiene mucha agua. Muchos otros pueblos sufren de agua, acá entra un tanto así de tubo que se va a la ciudad de Oaxaca, por ahí esta una caseta donde se reparte el agua que consume la ciudad, la que consume el pueblo y la que se va para la ciudad. Hay mucha agua y eso es lo importante.

Para casarse había que ponerse listo, en primer lugar, si tenía yo una casa de adobe y no tenía yo dispensándome la palabra, no tenía cama, utensilios que ocupe la mujer, ahora hay esa ventaja, que hay estufa, antes que, era con leña, no, va a llegar mi mujer aquí y creo que al mes se va. Si hubiera yo estudiado probablemente hubiera dejado la fábrica, así hicieron muchos muchachos, se fueron a estudiar y a buscar trabajo, muchos están por Oaxaca y se fueron a México." (Entrevista con el Sr. Esteban conocido como Félix en ese momento, enero 2019).

Si logramos trascender las palabras de Félix, comenzamos a entender las palabras de Nietzsche "La verdad objetiva de la ciencia es una creencia inveterada que tenemos por verdadera porque la necesitamos para vivir y sobrevivir. No existen hechos, sino sólo interpretaciones. (Ovejero A. 
2015). Cada visión depende de quien mira, y de la condición de vida que le rodea, así se forma su criterio, y es a través de la psicología social que podemos conocer la conducta humana a través del otro, y es así como nos conocemos a nosotros mismos y todo ello con la finalidad de mejorar nuestra calidad de vida, que solo observando el contexto de quien vive inmerso en aquello que queremos analizar nos permite interiorizar a través de sus palabras, sus experiencias, sus decisiones, el entender las formas presentes de vida hoy.

Asimismo, la Arquitectura y la Historia, en sus diferentes dimensiones, para poder mirar en una dirección deben complementarse, hacerse crecer, intercambiar criterios, trascender en la dimensión del tiempo y el espacio, y ahí conectar la experiencia del momento presente en el que se lleva a cabo la investigación. Y ahondando a través de la experiencia poder intercambiar conocimientos y experiencias que remite el tiempo.

\section{CONCLUSIONES}

La vida de los trabajadores de la fábrica a través del contenido histórico, la parte arquitectónica y la vida humana, estas tres dimensiones forman una amalgama y una riqueza que no es fácil interpretar, y sobre todo encontrar personas que les tocó vivir en estos espacios, más aún personas que en el S.XXI, puedan dar fe de los hechos históricos que ocurrieron en los siglos pasados. (Figura 6).

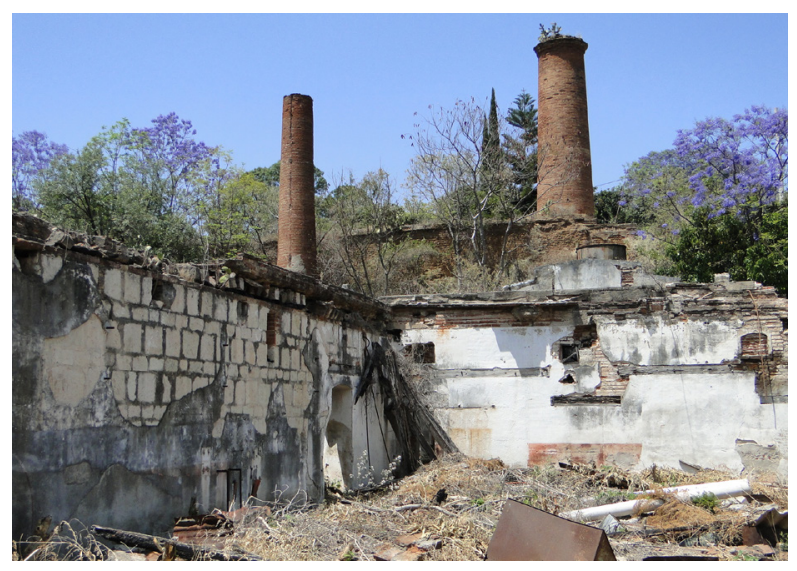

Figura 6. Ex Textilera San José, al fondo los chacuacos. Fuente: Archivo fotográfico propiedad de la autora 2019.

Es de considerar que la parte emotiva que remite este estudio permite analizar los archivos, desde las emociones a través de las historias de vida en sus diferentes momentos, que han cambiado considerablemente conforme el tiempo ha pasado, al enfrentar la necesidad de movilizarse desde otros puntos del estado de Oaxaca, la sierra, la costa, los mixes, diferentes climas, comidas, tradiciones, usos y costumbres, idiomas y comenzar a trabajar desde muy jóvenes, quince años la gran mayoría de ellos, para poder iniciar como aprendiz.

Movilizarse kilómetros, dejar sus tierras, empezar desde la nada, y continuar así durante más de 40 años, deseando entrar a la fábrica, aprender a trabajar y tener una seguridad, aunque eran sencillos aquellos tiempos deseaban tener otras condiciones de vida, hacerse de un espacio, tener las condiciones para ofrecerlas a sus familias, la historia que vivían los trabajadores, padres de familia, pobladores, hijos de trabajadores, esposas, que generó un devenir histórico en constante crisis, aun así tuvo sus momentos de abundancia, erosionado de valores conforme bajaban los salarios hasta no percibir un pago y tener que continuar $y$ poner de su propio dinero para seguir trabajando, de la perdida de las condiciones de vida, en aras del progreso, porque los salarios eran menores al mínimo. Las condiciones de vida en el mundo eran diferentes, muchos de ellos no soportaron las condiciones de la fábrica, emigraron cuando comenzaron las injusticias, los que pudieron salir de ahí, todos crecieron en diferentes ámbitos, mientras que en la fábrica el sindicato terminaba con todo lo que había en la fábrica para cobrarse lo que les debían por derecho hasta el día de hoy. Los dueños de la fábrica, un día lleno de ilusión y de abundancia se había esfumado junto con su visión, abandonaron la fábrica, la maquinara, a los trabajadores, el lugar y las deudas.

Así los vestigios hablan por sí mismos, la edificación, las memorias en la población, y esos tiempos nunca volvieron. Los años que se efectúa la investigación nos permite ver la riqueza a través de la pérdida, los valores humanos erosionados por las creencias irracionales, que justo en 1962 se produjeron las primeras aportaciones cognitivas que resaltan su importancia, la necesidad de ser gobernados bajo una autoridad de la cual permitan guiarse creando un nuevo valor, que prolonga el cuidado comunitario sin mermar la vida de cada individuo, asimismo, en la medida que las individualidades se suman, se restan, los valores humanos son indispensables en la colectividad y en su fin, y así mismo por ningún motivo debe anteponerse el logro de una meta por encima del individuo y su dignidad. 
La disposición y el amor por lo que se hace son fuerzas tremendas del ser humano, que no se encuentran en la soledad, sino en el acompañamiento del todos juntos como parte del mismo cuerpo, por metas que ennoblecen sus actos, que aparecen solamente en el ejercicio de la unión, como son la solidaridad, el trabajar en equipo, el ganar y la riqueza de todos. Hay que reflexionar que los espacios en que se trabajaban y en los que se habitaban por el hombre en aquel entonces en ocasiones no son considerados desde la psicología actual, las condiciones no fueron las óptimas históricas propias de los estilos de vida correspondientes a una clase social, definen el actuar frente al trabajo desde la concepción del espacio social que se presenta como la condición existencial básica del hombre, es ineludible hallar un lugar para desarrollar las actividades en las cuales satisfacer las necesidades vitales $\mathrm{y}$ expresarse como personas. $\mathrm{Y}$, para terminar, haciendo énfasis en la importancia de la voluntad y el amor en el trabajo laboral de aquellas manos artesanas que honestamente supieron ganarse la vida en las fábricas textiles en Oaxaca, sin importar sus temores y dinámicas de vida, quedando aún por responder. (Figuras 7 y 8 ).

\section{Agradecimientos}

Se agradece a las personas que aportaron sus vivencias en esta entrevista oriundos de San Agustín Etla Oaxaca y en especial a la aportación y colaboración para llevar a cabo las entrevistas Lic. Nancy Angélica Merlo Santos.

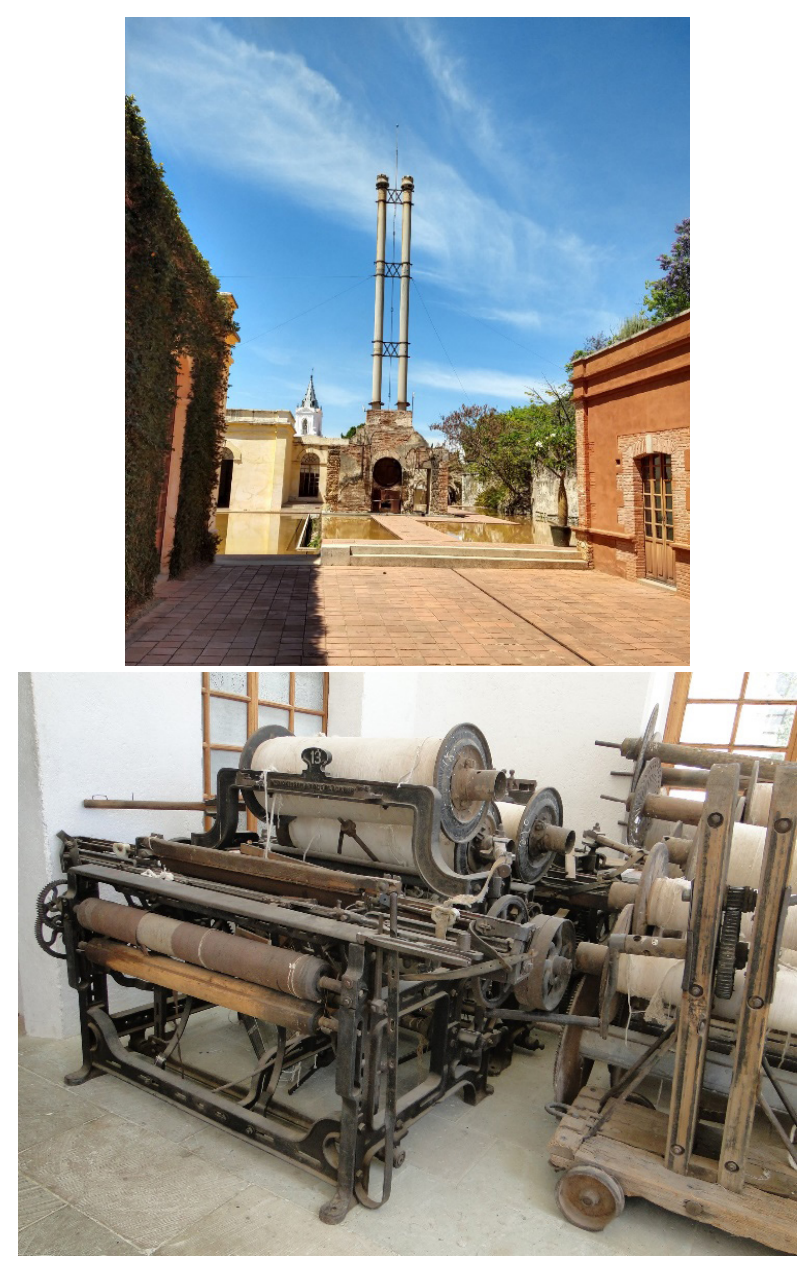

Figuras 7 y 8 . Patio exterior de la ex fábrica de hilados y tejidos la Soledad Vista Hermosa, hoy Centro de las Artes San Agustín Etla Oaxaca, y área interior maquinaria telar y de tejer.

Fuente: Archivo fotográfico propiedad de la autora 2019.

\section{REFERENCIAS}

Arroyo L, M., \& Cárcamo S, M. (2010). La evolución histórica e importancia económica del sector textil y del vestido en México. Economía y Sociedad, XIV (25), 51-68.

Camarena O. M., (2001) Jornaleros, Tejedores y Obreros. Historia social de los trabajadores textiles de San Ángel (1850-1930). Plaza Valdés Editores., 1ª edición México.

Clay S. H., Wakeley H. (1988). Psicología de la conducta industrial. Editorial Mc. Graw Hill. México.

Diario "El Oaxaqueño". (1936). Hemeroteca del Estado de Oaxaca.,

Gibbs, G. (2012) El análisis de datos cualitativos en la Investigación Cualitativa, Madrid, Morata. 
López - Memorias del habitar: Las condiciones de vida en el trabajo en fábricas textiles en San Agustín Etla Oaxaca

Höffner J. (1990). Manual de Doctrina social cristiana. Editora de Revistas S.A de C.V. México.

Hogg- Vaughan (2010). Piscología Social. Editorial Médica Panamericana 5ta Edición España.

Izcara Palacios, Simón Pedro (2014). Manual de investigación cualitativa. Fontamara.

López J.M. (1992). Conductismo. Revista de Psicología Práctica. España.

Manual de evaluación y entrenamiento de las habilidades sociales. (1993). Editorial siglo XXI. De España Editores.

Martínez V., (1985). La Revolución en Oaxaca 1900 - 1930. Tipografía, Diseño e Impresión, S.A. de C.V., Instituto de Administración Pública de Oaxaca.

Maykut, P. \& Morehouse R., (1996), Begining Qualitative Research. A Philosophic and Practical Guide, Londres, The Falmer Press.

Myers D., (1995). Psicología Social. Mc. Graw Hill 4a Edición. México.

Miño G. M., (1983). Historia Mexicana. Volumen 32, No. 4. Colegio de México. Recuperado de: https:///www. jstor.org/stable/25135837

Morales J.F., Domínguez C., Casal H., Gómez A., Gavira E. (2008) Método, teoría e investigación en psicología social. Editorial Pearson. Pertice Hall.

Neri C. A. (2004). Migración, globalización y perspectiva poblacional en la zona indígena Cuicateca, Oaxaca. El Cotidiano [Internet];20(126):0. Recuperado de: http://www.redalyc.org/articulo.oa?id=32512612

Olmedo J., (2007). Orientación social desde una ética mundial. Editorial San Pablo. Argentina.

Ovejero A., (2010-2015). Psicología Social. Algunas claves para entender las habilidades sociales. Biblioteca Nueva.

Schultz D., (1992). Psicología industrial. Editorial Interamericana. 3era. Edición. México.

Southworth, J. R. (1901), Oaxaca y Puebla Ilustrada. Recuperado de: http://cdigital.dgb.uanl.mx/ la/1020133522/1020133522.PDF

Tello, C. (2009). Sobre la crisis económica. Este País.

Taylor, S.J y R. Bogdan (1990) Introducción a los métodos cualitativos de investigación. Barcelona, Paidós.

Velasco, G. J. (2011) Capitalismo y modernización en Oaxaca. La industria textil durante la Reforma y el Porfiriato. Instituto Politécnico Nacional. 1ª Edición México.

Worchel S. Cooper J., Goethals G., Olson J. (2003). Psicología Social. Editorial Thomson. 